\title{
Efecto de la modulación del receptor nuclear PPAR $\gamma$ en la diferenciación de células de preadipocitos de fibroblastos
}

\author{
Luis Gustavo Celis, Diana Vargas Trujillo' PhD y Fernando Lizcano Losada, PhD.
}

Laboratorio de Biología Molecular Facultad de Medicina, Universidad de La Sabana

Correspondencia: luis.celis@unisabana.edu.co

Recibido: 16-08-06 / Aceptado: 12-09-06

\begin{abstract}
Resumen
La adipogénesis a partir de preadipocitos de fibroblastos de ratón es evaluada mediante la utilización de Rosiglitazona e Insulina, para ello se incuban preadipoctos de ratón de la línea celular 3T3.-L1 en presencia de un cóctel de diferenciación con Rosiglitazona e Insulina, realizándose observaciones entre los 0 y 10 días de diferenciación con una frecuencia de cada 2 días. El proceso de diferenciación de los adipocitos fue valorado mediante la cantidad de triglicéridos presentes de las células grasas mediante métodos cualitativos a través de tinciones y métodos cuantitativos producto de la extracción de los ácidos grasos con isopropanol y la medición de la absorbancia a $510 \mathrm{~nm}$.

Los resultados obtenidos nos permitieron corroborar el efecto adipogénico tanto de la Rosiglitazona como de la Insulina, aunqueambos presentaron diferencias en su capacidad adipogénica, dado que la Rosiglitazona es un ligando sintético del receptor nuclear PPAR y cuya activación induce la expresión de los genes involucrados en la adipogénesis mientras que la insulina actúa sobre el receptor de membrana para el factor de crecimiento tipo Insulina (IGF-1) cuya ruta no activa directamente el receptor nuclear PPAR $\gamma$ trayendo como consecuencia un proceso adipogénico más lento con respecto a la Rosiglitazona. Estos resultados nos permitirán en el futuro el desarrollo de nuevos medicamentos para el tratamiento de enfermedades como la obesidad y la diabetes tipo 2.
\end{abstract}

Palabras claves: adipocitos, adipogénesis, ateroesclerosis, diabetes tipo 2, obesidad, Rosiglitazona.

\begin{abstract}
Adipogenesis from preadypocites of mouse fibroblasts is evaluated by using Roziglitazone and Insulin. To that effect, mouse preadipocytes of the cellular line 3T3-L1 are incubated in a differentiation cocktail with Rosiglitazone and Insulin. Observations are made between 0 and 10 days with a frequency of two days. The adipocytes differentiation process was valued through the amount of present triglycerides from the fatty cells using qualitative methods by dying and quantitative methods from the extraction of fatty acids with isopropanol and measuring absorbance at $510 \mathrm{~nm}$.
\end{abstract}


The results obtained allowed us to confirm the adipogenic from Rosiglitazone and from Insulin, althoughboth showed differences in their adipogenic ability because Rosiglitazone is a synthetic PPAR $\gamma$ nuclear receptor ligand. When activated, it induces the expression of the genes involved in the adipogenesis process while insulin acts on the membrane receptor for the growth factor insulin type (IGF-1) which route does not activate the PPAR $\gamma$ nuclear receptor directly resulting in an adipogenic process slower when compared to Rosiglitazone. These results will allow us to develop new medicines in the future for the treatment of diseases such as obesity and type- 2 diabetes.

Key words: adipogenesis, adypocites, atherosclerosis, obesity, Rosiglitazone, type-2 diabetes.

\section{Introducción}

El papel de los adipocitos en la actualidad dista del que se encontraba en los antiguos textos de histología que los señalaban como células exclusivamente para almacenar ácidos grasos. En la actualidad es considerada como una glándula que produce varias moléculas biológicamente activas tales como el receptor para factor de crecimiento tipo insulina (IGF-1), APO E, Adiponectina, Esteroides, TGFa, Factor tisular y otros $(1,2)$.

La elucidación del proceso de diferenciación de los adipocitos podría contribuir a la comprensión de distintas patologías asociadas a los trastornos funcionales de las células grasas. Este proceso es regulado entre otros por la activación del receptor de proliferación de los peroxisomas $\gamma$ (PPAR $\gamma$ ), que pertenece a la subfamilia de receptores nucleares de hormonas que forman parte de la familia de los factores de transcripción $(3,4)$.

Este receptor presenta dos dominios, uno que le permite unirse al ADN, y otro, que reconoce un ligando específico, en este caso ácidos grasos. Para ejercer su acción también se requiere que forme un heterodimero con el ácido retinoico (5). Desde hace mucho tiempo se conoce la capacidad de las Thiazolinedionas de unirse al dominio del ligando del receptor PPAR $\gamma$ e inducir la diferenciación de preadipocitos de ratón a adipocitos maduros, por lo que se comportan como agonistas de PPAR $\gamma$ y, por lo tanto constituyen un buen modelo de estudio de cómo ocurre este proceso (4).
Recientemente se ha observado que la proteína inhibidora de la diferenciación de la célula muscular (EID-1), actúa como inhibidor de la actividad acetilasa de p300, permitiendo bloquear la acción de PPAR $\gamma$ unido a Rosiglitazona para favorecer la producción de osteoblastos $(5,6)$.

Otro mecanismo que puede inducir la diferenciación de la célula grasa está mediado por la acción de la insulina que es capaz de interaccionar con el receptor de membrana para factor de crecimiento tipo insulina (IGF-1) que actúa principalmente sobre el sustrato del receptor de insulina (IRS-1) e IRS 2 que activan la fosfatidilinositol 3- quinasa (PI-3K) y la proteina kinasa $\mathrm{B}$, que a través de otra serie de reacciones conducirá a la activación de ERK (extracellular signal regulated quinasa) que su vez tambén activa varios factores de la transcripción que estimularán la expresión de los genes involucrados en la proliferación y diferenciación celular (7).

El propósito de nuestro trabajo es el de comparar el efecto adipogénico de la Rosiglitazona con respecto a la insulina producto de la activación del receptor nuclear PPAR $\gamma$ utilizando la línea celular 3T3-L1 (Preadipocitos de fibroblastos de ratón).

\section{Materiales y métodos}

Línea Celular. Se utilizó la línea celular de fibroblastos (preadipocitos) de ratón 3T3L1 proveniente 
de la colección ATCC obtenida a partir de un extracto continuo de $\mathrm{T} 3$, caracterizada por ser células unipotentes y que tienen la capacidad expresar receptores de insulina y que han sido ampliamente utilizadas como modelo para el estudio de la adipogénesis (8).

Cultivo Celular. Se realizó el cultivo de líneas celulares 3T3-L1 (preadipocitos de ratón) en medio DMEM, FBS al 10\% y Penicilina y Estreptomicina al $1 \%$ y se incuban durante 48 horas a una temperatura de $37^{\circ} \mathrm{C}$ y atmósfera con $95 \%$ de aire y $5 \%$ de $\mathrm{CO} 2$, formándose una monocapa.

Posteriormente se realizan subcultivos mediante una digestión enzimática con tripsina y EDTA durante $3 \mathrm{mi}$ nutos en incubadora de $\mathrm{CO} 2$ y se siembran 3 cajas de petri por unas 48 horas para formar nuevamente una monocapa de células con un $100 \%$ de confluencia.

Diferenciación celular. Se agrega un cóctel para inducir la diferenciación, utilizándose dos inductores distintos Rosiglitazona a $1 \mathrm{mM}$ e insulina a 1,66 mM, además se añaden $1 \mathrm{mM}$ de Dexametasona para activar el factor de la transcripción $\mathrm{C} / \mathrm{EBPb}$ y $0.5 \mathrm{mM}$ de Metil isobutil xantina que incrementa los niveles de AMPc por inhibición de la fosfodiesterasa (9).

Luego de 48 horas se cambia el medio de cultivo + cóctel de diferenciación, por sólo medio de cultivo + Rosiglitazona, ó medio de cultivo + insulina. Esto para el mantenimiento de las células y eliminación de desechos.

Finalmente se realizan observaciones a $\operatorname{los} 0,2,4$, 6, 8 y 10 días después de la aplicación del cóctel de diferenciación.

Determinación de triglicéridos: Para comprobar la diferenciación de la célula grasa se realiza la determinación de triglicéridos por un método cualitativo que consiste en la tinción de las células con rojo aceite que colorea los triglicéridos (8) y por un método cuantitativo (10) mediante extracción de lípidos con

www.unicolmayor.edu.co
$5 \mathrm{ml}$ de isopropanol para luego leer la absorbancia del extracto a $510 \mathrm{~nm}$ en un biofotómetro Eppendorf .

\section{Análisis Estadístico}

Para verificar la significancia estadística de los resultados dado el número de replicas que se realizaron se procedió a realizar pruebas no paramétricas.

La prueba utilizada fue la de Kruskal-Wallis (se utilizó para ello el programa stat view ${ }^{\mathrm{TM}}$ ), que es un tipo de ensayo en el que la hipótesis nula consiste en que todas las poblaciones son idénticas con respecto a la alternativa, que plantea que las poblaciones tienden a suministrar valores observados mayor que los otros (11).

\section{Resultados}

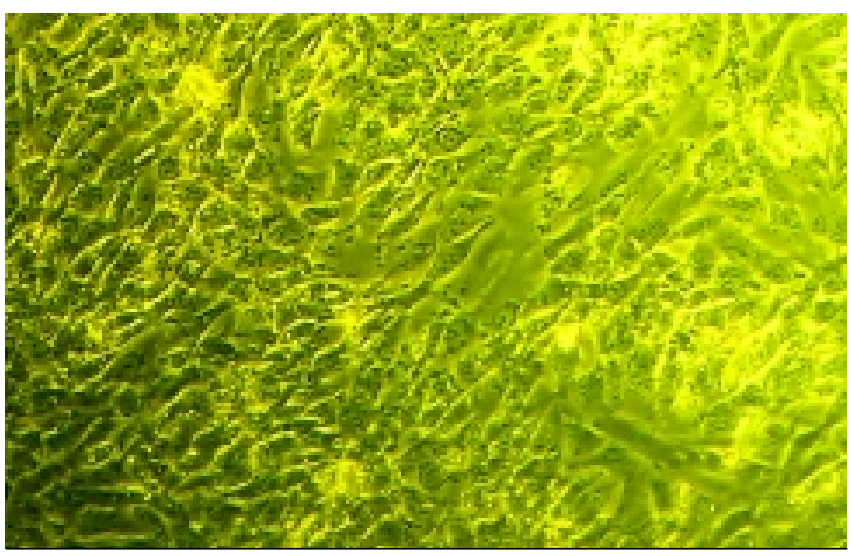

Figura 1. Cultivo de preadipocitos de ratón sin diferenciar en medio DMEM 100X, nótese el aspecto fusiforme de las células.

En la Figura 1 es posible apreciar las células en cultivo sin diferenciar una vez se han descongelado y han formado la monocapa.

Los resultados obtenidos con Rosiglitazona nos permiten obeservar como las células empiezan a cambiar de forma y a diferenciarse entre los 6 y los 10 días (Figuras 2, 3 y 4), lo cual puede ser valorado a través de la acumulación de triglicéridos en las células de preadipocitos mediante la tinción de rojo aceite (Figura 5) o cuantificando los mismos por espectrofotometría.

En las células tratadas con insulina también se presentó también la adipogénesis pero en menor proporción (Figura 6), lo cual se confirma por los 


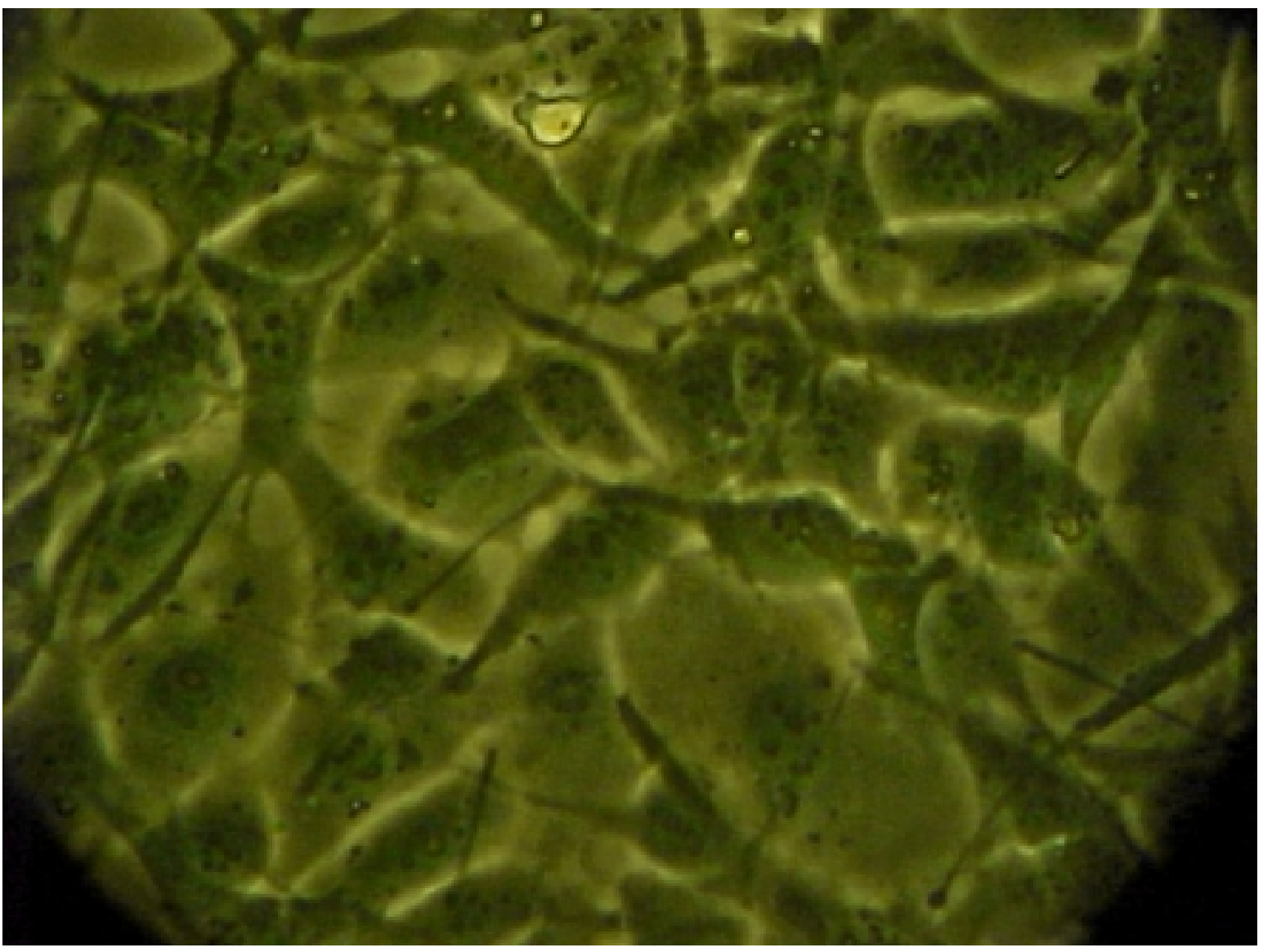

Figura 2. Preadipocitos de ratón diferenciándose por acción de Rosiglitazona, obsérvese el cambio de forma. Microscopio invertido 100X.

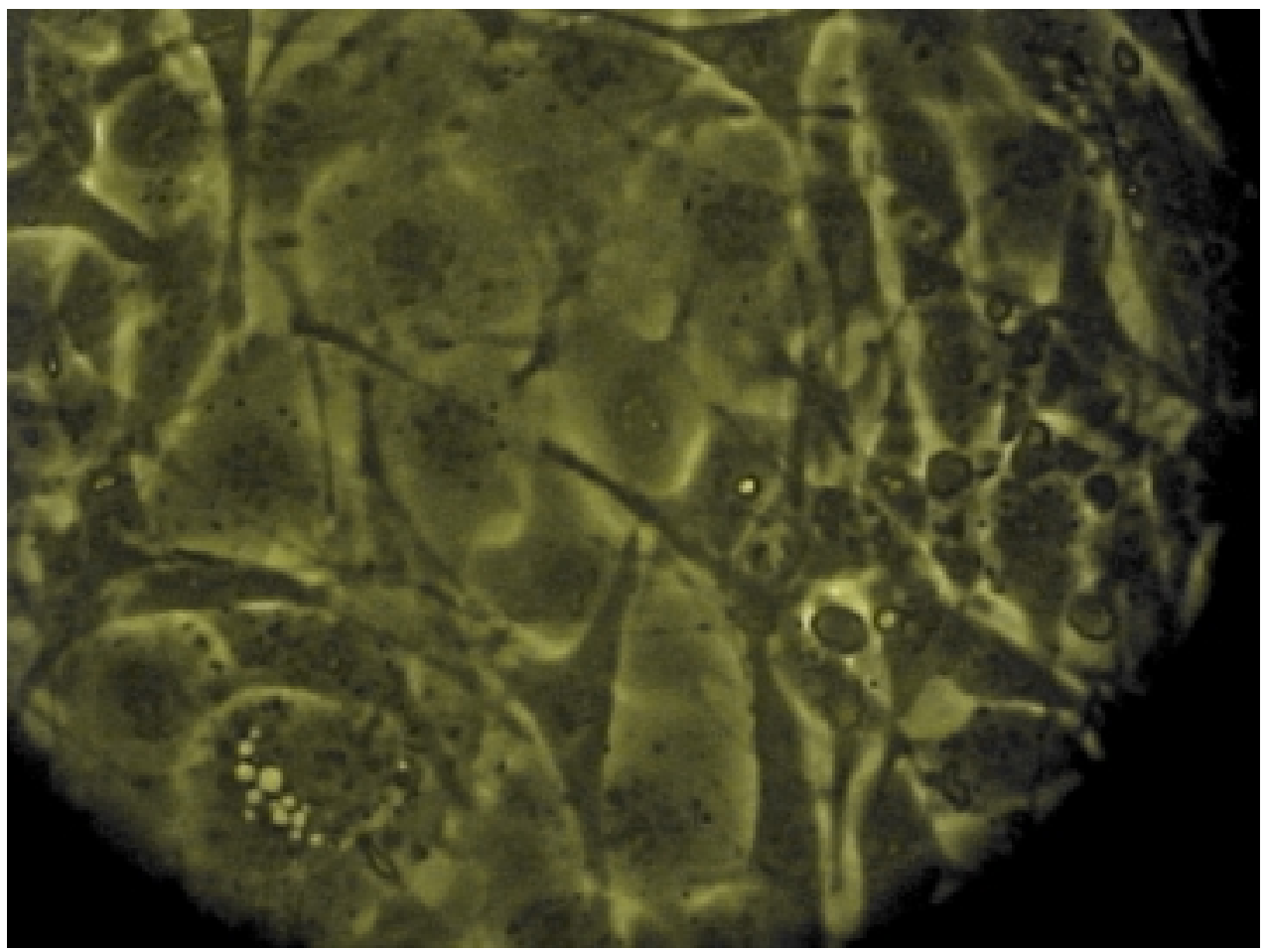

Figura 3. Preadipocitos de ratón diferenciándose por acción. de la Rosiglitazona, obsérvese la acumulación de ácidos grasos dentro de la célula. Microscopio invertido 100X. 


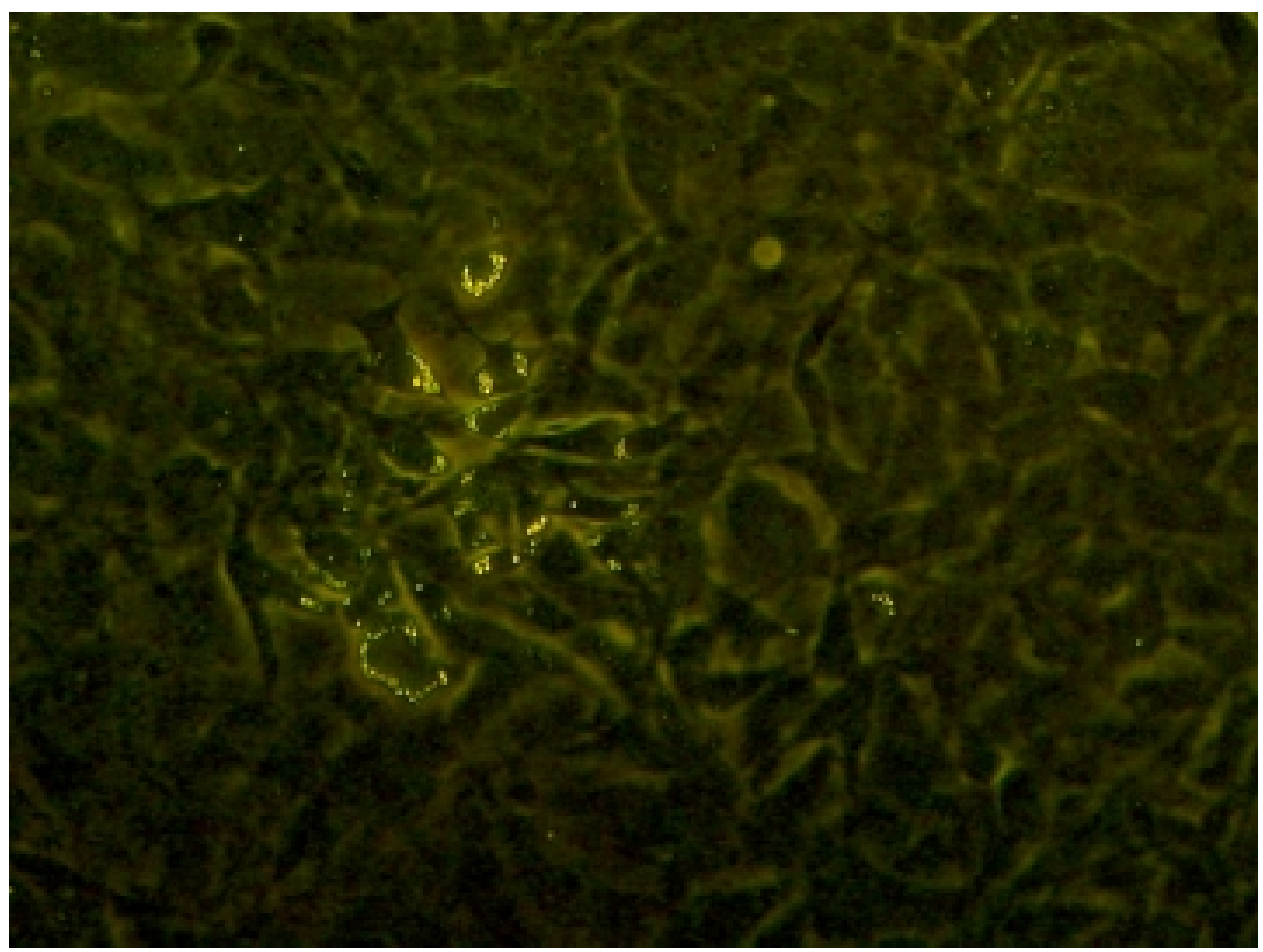

Figura 4. Preadipocitos de ratón diferenciándose por acción de la Rosiglitazona, obsérvese la acumulación de ácidos grasos dentro de la célula. Microscopio invertido 100X.

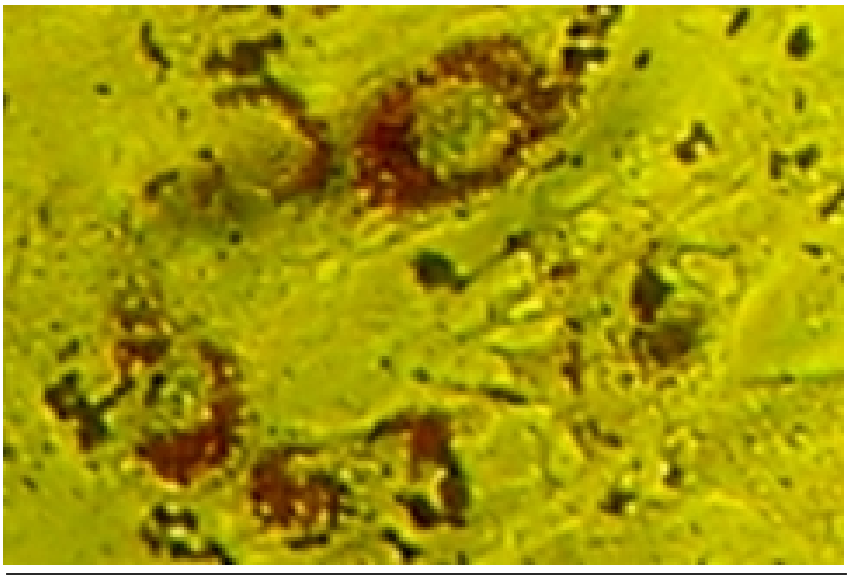

Figura 5. Preadipocitos de ratón tratados con rosiglitazona a los 10 días de diferenciación, obsérvese la tinción con rojo aceite para ácidos grasos. Microscopio invertido 10X.

resultados obtenidos con la tinción de rojo aceite (Figura 7) y por los resultados de la cuantitifcación de lípidos. Obteniéndose que para el caso de la Rosiglitazona la cantidad de lípidos obtenidos es 3.21 veces más con respecto a las células sin diferenciar y 1.41 con respecto a la insulina, mientras que la insulina fue de 2.28 veces más con respecto al control (Figura 1).

\section{Discusión}

Los resultados obtenidos demuestran la capacidad de la Rosiglitazona y de la Insulina de promover la adipogénesis, lo cual puede ser evidenciado mediante los cambios morfológicos que se presentan en las células y por la acumulación de triglicéridos determinados, tanto cualitativa, como cuantitativamente.

Sin embargo, el proceso de adipogénesis mediado por la Rosiglitazona es mayor con respecto al obtenido con la Insulina, debido a que la Rosiglitazona actúa como un ligando sintético del receptor nuclear PPARg, cuya activación promueve la expresión de genes específicos en los adipocitos involucrados con la adipogénesis. Estos hallazgos confirman el papel de PPARg como el regulador maestro de la adipogénesis. Esto también se demuestra cuando al trabajar con ratones con una mutación inactivante para el locus PPARg2 se encuentra que es letal, por lo que este receptor juega también un papel importante en el mantenimiento de las funciones metabólicas y endocrinas del tejido adiposo blanco, además de que es necesario para 


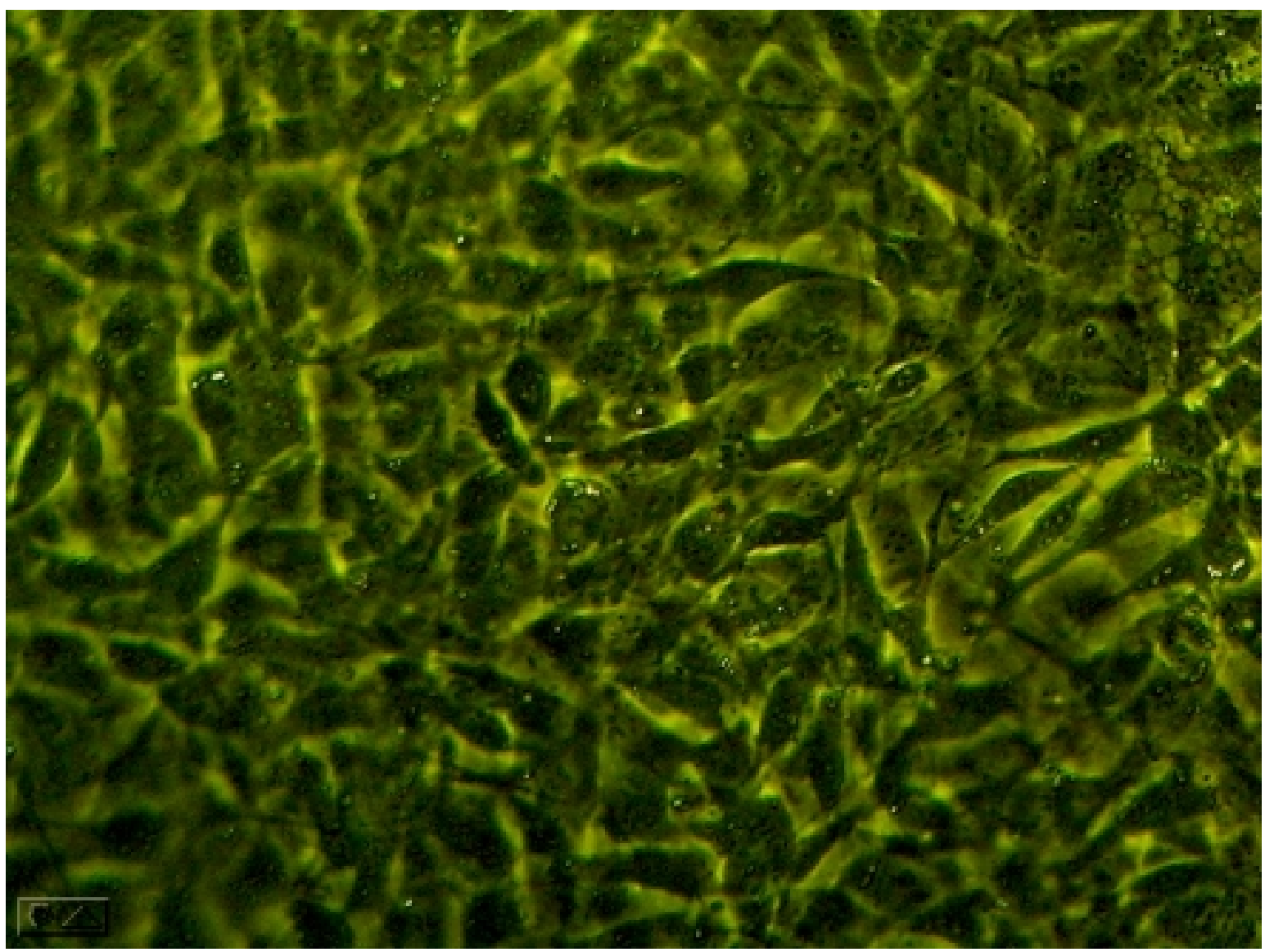

Figura 6. Preadipocitos de ratón diferenciándose por acción de la Insulina, obsérvese la acumulación de ácidos grasos dentro de la célula. Microscopio invertido 100X.

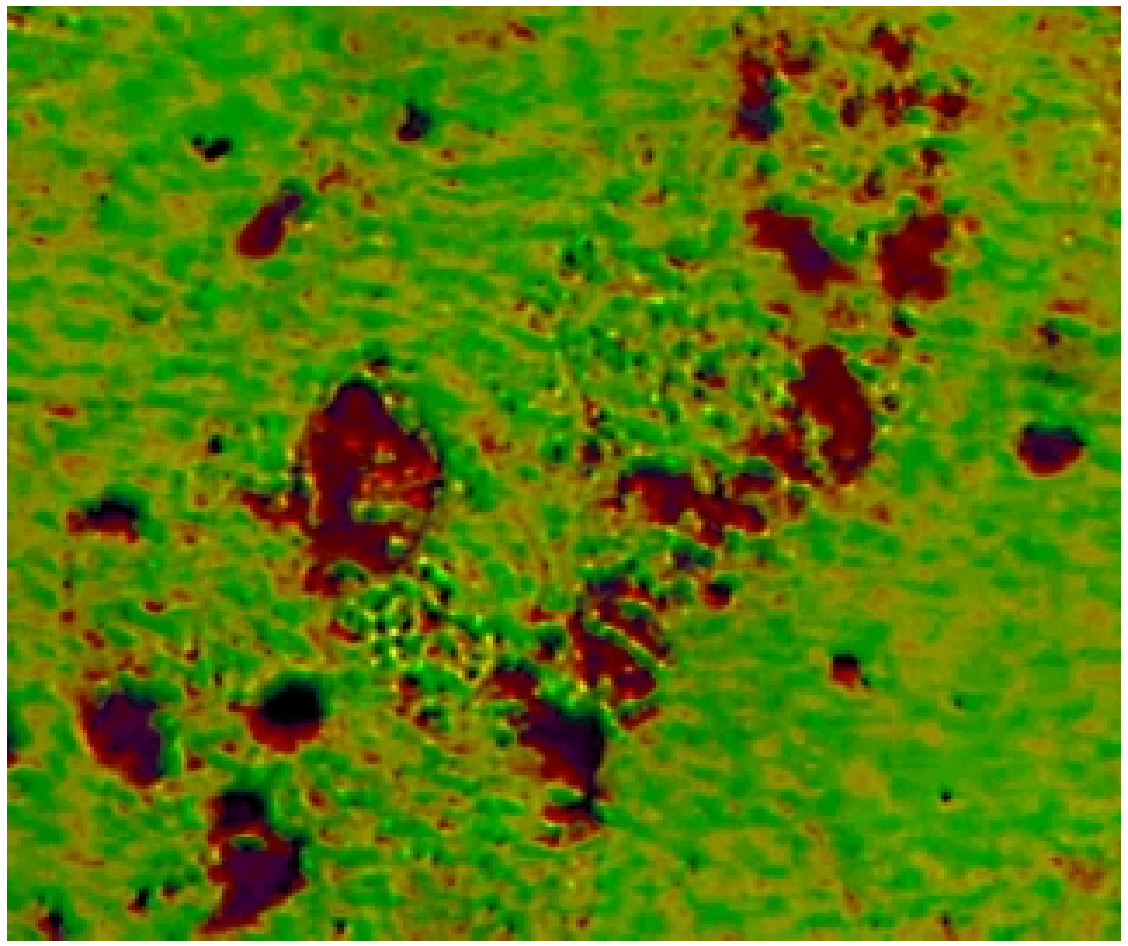

Figura 7. Preadipocitos de ratón tratados con Insulina a los 10 días de diferenciación, obsérvese la tinción con rojo aceite para ácidos grasos. Microscopio invertido 10X. 


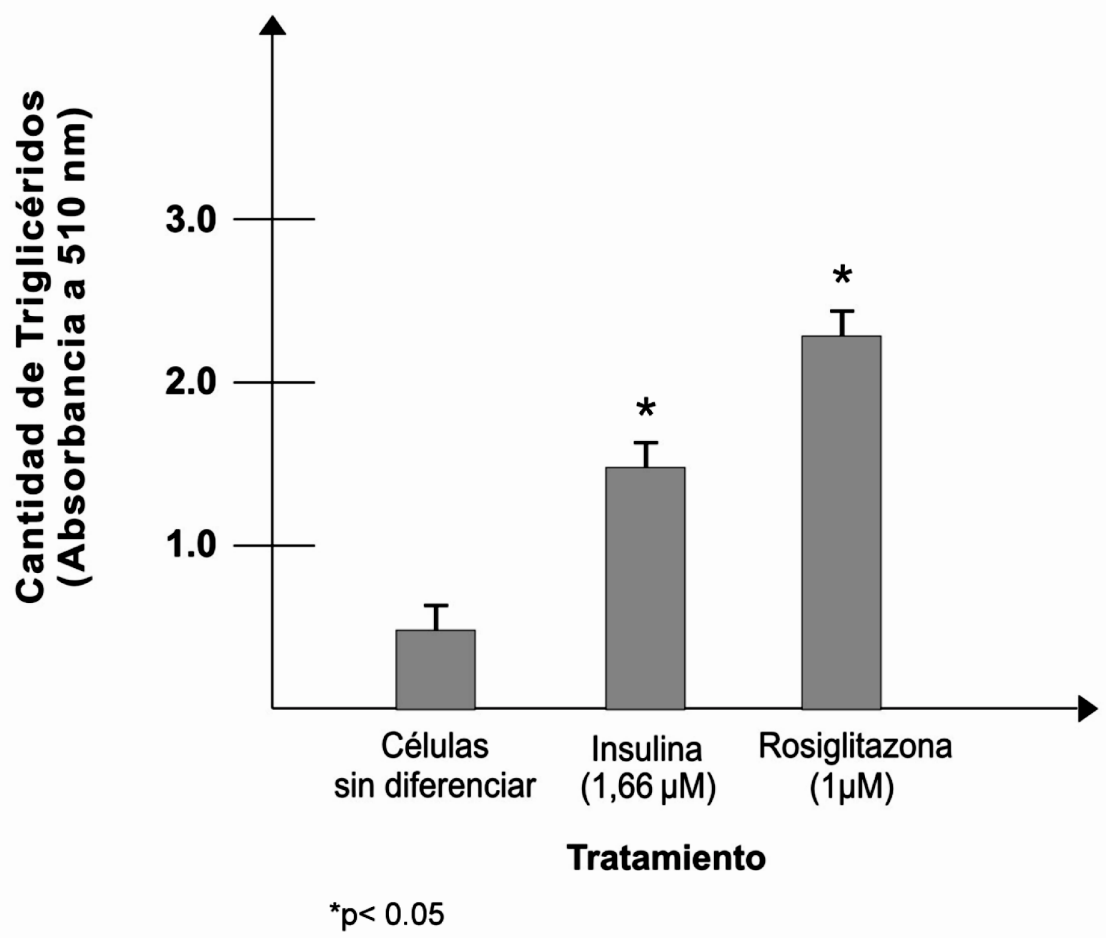

Grafica № 1. Cantidad de Triglicéridos encontrados en las células diferenciadas tratadas con Rosiglitazona e Insulina con respecto a las células sin diferenciar no tratadas, el resultado corresponde al promedio de las observaciones realizadas.

el mantenimiento del estado de diferenciación (12).

Por otra parte, el mecanismo de acción de la insulina está mediado por su interacción con el receptor de membrana para el factor de crecimiento similar a insulina 1 (IGF-1). Dado que éste se expresa en etapas tempranas de la adipogénesis, desencadena una serie de reacciones principalmente de fosoforilación de proteínas que conducen a la activación de la vía Map quinasa (Mitogen Activating Protein) y de otras proteínas que a su vez activarán o inhibirán varios factores de la transcripción para finalmente estimular la expresión de los genes involucrados en la proliferación y diferenciación celular $(13,14,15,16)$. Entre estos se destacan Necdin, Creb, GATA 2, Foxo 1 y FOXA2, cuyos blancos aún no son conocidos (7). Por lo tanto el efecto adipogénico de la insulina es más lento e indirecto dado qué, además del receptor de membrana, se requiere de la acción de proteínas fosoforilasas y de otro tipo para la adipogénesis.

Nuestros resultados coinciden con los obtenidos por Fu y col. 2005 (17), que diferenciaron preadipocitos
3T3-L1 utilizando Rosiglitazona o insulina como inductores para estudiar la expresión de los genes involucrados en la diferenciación y parcialmente con los resultados obtenidos por Vargas y Lizcano (18) en el que obtienen que la Rosiglitazona induce dos veces más la diferenciación de los adipocitos comparados con un agonista parcial de PPARg, el Telmisartan y 5 veces más con respecto a las células sin diferenciar (19).

Igualmente, se ha observado que los preadipocitos a medida que se diferencian aumentan hasta en 20 veces el número de receptores para la insulina por lo que ésta se constituye en una ruta alternativa para la diferenciación celular (14).

Estos resultados nos permiten la comprensión de la fisiopatología de los adipocitos, en especial el papel del receptor PPARg en este proceso, lo cuál permitirá realizar intervenciones en enfermedades como la ateroesclerosis, la diabetes tipo 2 y la obesidad, mediante la búsqueda de agonistas para este receptor nuclear, al igual que el diseño de nuevas estrategias de tratamiento 
en enfermedades como lipodistrofia y resistencia a la insulina $(19,20)$. Un ejemplo de esto lo constituye el trabajo de Crandall y col. (2006), quienes al utilizar pequeñas moléculas para inactivar el Inhibidor del Activador del Plasminogéno 1 (PAI-1) en cultivos de preadipocitos humanos eran capaces de reducir la diferenciación y por lo tanto prevenir el desarrollo de la obesidad por dieta, sugiriendo que la inhibición farmacológica de este factor puede ser utilizada en las enfermedades asociadas con la expansión de la masa de tejido adiposo (21).

\section{Referencias}

1. González, M., Bastidas, B. E., Ruiz, B., Godinez, S. y Panduro, A. (2002). Funciones endocrinas de la célula adiposa. Revista Endocrinología y Nutrición 10(3): 140-146.

2. Lizcano, F. y Martinez, F. Diabetes: Bases moleculares. Fisiología y fisiopatología. En Fundamentos moleculares en medicina, Editor Fernando Lizcano Losada, Editorial El Manual Moderno y Universidad de La Sabana, Bogota 2005.

3. Farmer, S. R. Regulation of the Cell Cycle by Peroxisome Proliferator - Activated Receptor Gamma (PPAR ?).En Steroid Hormones and Cell Cycle Regulation Editado por Kerry L. Burnstein Kluwer Academic Publishers Boston 2002, Cap. 11, pags. 191-205.

4. Francis, G. A., Fayard, E., Picard, F. y Auwerx (2003). Nuclear Receptors and The Control of Metabolism. Annu. Rev. Physiol. 65: 261-311.

5. Vargas, D., Díaz, M., Martinez, I. y Lizcano, F. (2004). Valoración de la actividad de PPARg en células humanas derivadas de osetosarcoma. Revista Colombiana de Osteología y Metabolismo Mineral Vol. 3(2):66-70.

6. Vargas, D., Díaz, M., Martinez, I. y Lizcano, F. EID-1 protein cause a decrease on PPARg ligand-dependent transcriptional activation (2004). In International Proceedings of 12 th. International Congress of Endocrinology, pags. 535-539.

7. Rosen, E. D. y MacDougald, O. A. (2006). Adipocyte differentiation from the inside out. Nature Reviews/Molecular Cell Biology Vol. 7: 885-896.

8. Student, A. K., Hsu, R. Y. y Lane, M. D. (1980). Induction of Fatty Acid Synthetase Synthesis in Differentiating 3T3-L1 Preadipocytes. The Journal of Biological Chemistry Vol. 225 (10): 4745-4750.
9. Fu, M., Sun, T., Bookout, A. L., Downes, M., Yu, R. T., Evans, R. M. and Mangelsdorf, D. J. (2005). A Nuclear Receptor Atlas: 3T3-L1 Adipogenesis. Molecular Endocrinology 19(10):2437-2450. The Journal Clinical Investigation Vol. $116(3)$ : $581-589$.

10. Xiang-hui, L., Zhang, J., Sui, S. y Yang, M. (2005). Effect of daidzin, genistin, and glycitin on osteogenic and adipogenic differentiation of bone marrow stromal cells and adipocytic transdifferentiation of osteoblasts. Acta Pharmacologica Sinica Vol. 26 (9): 1081-1086.

11. Zimmerman, F. J. Estadística para Investigadores. Editado por la Escuela Colombiana de Ingeniería y la Universidad de La Sabana, Bogotá 2004, Cap. 16, págs. 353-361.

12. Cock, T. y Auwer, J. (2004). PPARg Fundamental Rol in Adipogenesis. Proceedings of the 13th Internacional Atheroesclerosis Symposium Vol.1262, pag. 4750.

13. Lizcano, F. y Martinez, F. Diabetes: Bases moleculares. Fisiología y fisiopatología. En Fundamentos moleculares en medicina, Editor Fernando Lizcano Losada, Editorial El Manual Moderno y Universidad de La Sabana , Bogota 2005 , Cap. 8., Pags. 173-190.

14. Viveros Cortés, A., Lavoada Molina, H. y Bastarrachea Sosa, R. (2002). Influencia endocrina y paracracrina sobre la adipogenesis. Revista de Endocrinología y Nutrición Vol.10(3):151-164.

15. Rodríguez de la Concepción, M. L. (2002). Diferenciación Adipocitaria y Factores Reguladores de la Biogénesis Mitocondrial. Efecto de los Fármacos Retrovirales. Memoria presentada para optar al Título de Doctor en Biología. Universidad de Barcelona, Barcelona 2002.

16. Vidal, A. J. (2000). Papel de los PPAR en el tratamiento de dislipidemias asociada a la diabetes mellitus tipo II. Cardiovascular Risk Factors Vol. 9(1): 11-19.

17. Fu, Y., Luo, N., Klein, R. L. y Garwey, W. T. (2005). Adiponectin promotes adipocyte differentiation, insulin sensivity, and lipid acumulation. J. Lipid. Res. Vol. 46(7): 1369-1370.

18. Vargas, D., Díaz, M., Martinez, I. y Lizcano, F. Efecto de diferentes agonistas de PPARg sobre la diferenciación del adipocito. VIII Congreso Nacional de Endocrinología, Bogotá D. C., Agosto 2005.

19. Vargas T., D. y Lizcano, F- (2006). Efecto de la Rosiglitazona y Telmisartan en la diferenciación de células adiposas. Nova Vol. 3(4): 107.

20. Semole, R. K., Chatterjee, V. K. y O' Rahilly, S. O. (2006). PPARg and human metabolic disease. The Journal Clinical Investigation Vol. 116(3): 581-589.

21. Crandall, D. L., Quinet, E. M., El Ayachi, S., Hreha, A. L., Leik, C. E., Savio, D. A., Juhan-Vague, I. y Alessi, M. (2006). Modulation of Adipose Tissue Development by Pharmacological Inhibition of PAI-1. Arterioscler. Thromb. Vas. Biol. Recuperado el 6-12-2006. http://www.atvbaha.org. 